\title{
Comparison of the immediate effect of hamstring stretching techniques on hamstring muscle range of motion, pressure pain threshold and muscle tone
}

\author{
June-Su Yu ${ }^{a}$, Won-Seob Shin ${ }^{a, b}$ \\ aDepartment of Physical Therapy, Graduate School of Health and Medicine, Daejeon University, Daejeon, Republic of Korea \\ ${ }^{\mathrm{b}}$ Department of Physical Therapy, College of Health and Medical Science, Daejeon University, Daejeon, Republic of Korea
}

\begin{abstract}
Objective: This study was conducted to compare the immediate effect of hamstring stretching techniques of static stretching, proprioceptive neuromuscular facilitation (PNF) hold-relax and PNF irradiation on the hamstring muscle.

Design: Three-group pretest-posttest design.

Methods: Fifty-one subjects with shortened hamstrings were randomly assigned to the static stretching group ( $\mathrm{n}=17)$, PNF hold-relax group $(n=17)$, and the PNF irradiation group $(n=17)$. All subjects performed an active knee extension (AKE) test to assess for the lower extremity with a shortened hamstring. The static stretching group performed stretches by lifting their leg to the maximum extent (3 times, 30 seconds). The PNF hold-relax group performed maximal isometric contraction against the experimenter's resistance ( 3 times, 10 seconds). The PNF irradiation group performed maximum isometric contraction against the experimenter's resistance toward the direction of the body ( 5 times, 5 seconds). The pre and post-tests measured range of motion (ROM), pressure pain thresholds (PPT) and muscle tone.

Results: There were significant differences in ROM and PPT between pre and post intervention in each group ( $p<0.05)$. There was a significant difference only in the ROM among groups $(p<0.05)$. Post-hoc analysis showed that the changes in ROM occurred in the order of the PNF hold-relax group, static stretching group and PNF irradiation group $(p<0.05)$.

Conclusions: The findings of this study suggest that the PNF irradiation technique may improve ROM and may be used to improve ROM similar to other stretching techniques. Therefore, the PNF irradiation technique could be included in stretching programs and can be used as a suitable stretching method depending on the situation.
\end{abstract}

Key Words: Hamstring muscle, Irradiation, Range of motion, Static stretching

\section{Introduction}

Muscle flexibility is important for the normal functioning of a person. Limited flexibility reduces the functional level of the musculoskeletal system and can significantly be related to injury [1]. Reduction in flexibility has been pointed out as the cause of various injuries [2], and with people who spend a lot of time sitting in a chair, the shortening of the hamstrings is associated with poor posture, back pain, and walking difficulties, causing various dysfunctions [3]. In ad- dition, injuries of the hamstring muscles are known to occur in athletes of various sports such as land sports, water skiing, dance, soccer, and rugby [4].

Previous studies have applied a number of methods to enhance flexibility, including massage, muscle energy techniques, myofascial release techniques, proprioceptive neuromuscular facilitation (PNF), and static stretching $[1,5,6]$. Stretching is necessary to manage muscle stiffness and maintain normal muscle length, and by stretching soft tissues such as muscles, tendons, ligaments, it increases joint range,

Received: 23 September, 2019 Revised: 30 October, 2019 Accepted: 5 November, 2019

Corresponding author: Won-Seob Shin (ORCID https://orcid.org/0000-0002-6515-7020)

Department of Physical Therapy, College of Health and Medical Science, Daejeon University, 62 Daehak-ro, Dong-gu, Daejeon 34520, Republic of Korea Tel: 82-42-280-2294 Fax: 82-42-280-2295 E-mail: shinws@dju.kr

(c) This is an Open-Access article distributed under the terms of the Creative Commons Attribution Non-Commercial License (http://creativecommons.org/licenses/ by-nc/4.0) which permits unrestricted non-commercial use, distribution, and reproduction in any medium, provided the original work is properly cited.

Copyright (๑ 2019 Korean Academy of Physical Therapy Rehabilitation Science 
maintains and improves flexibility, improves body function, and prevents injuries [1,7]. The effects of these stretching methods have already been demonstrated in several previous studies $[1,8,9]$, and in the previous studies these effects were compared in regards to range of motion (ROM), pressure pain threshold, and muscle tension [7].

Sherrington [10] reported that the stronger the muscle contraction, the greater the relaxation effect. Accordingly, the PNF irradiation method emphasizes techniques for indirectly strengthening weak segments or relaxing after performing indirect isometric contractions with muscle contraction force generated by applying resistance to body segments [11]. The promotion principle of the PNF irradiation promotion method is the concept of dissipation through resistance, which refers to the diffusion of energy from the primary synergists to the secondary antagonistic muscles, and is used indirectly instead of directly at the target site [12]. Among them, the method of applying the lower limb pattern of the PNF [13] and changing the muscle activity of the lower limbs by applying resistance to the upper extremities through the PNF irradiation method [14] have been shown to be clinically effective on indirectly solving problems occurring in the trunk and neck.

The method of using the dissipation effect shows the result that the muscle activity of the target site can be indirectly increased by using the body segmental contraction from a different site. This is the result of the mobilization of synergistic muscles and it is a concept that exercise overflow in strong body segments increases and enhances the activity of the exercise unit $[12,14]$. However, the majority of the previous studies on increasing flexibility have been conducted on evaluting hamstring flexibility using the static stretching and PNF-hold relax techniques, however, studies using indirect methods are limited to studies in which only some changes in muscle activity have been examined $[14,15]$.

Therefore, the purpose of this study was to investigate whether the change of muscle activity of the lower limbs caused by the application of the dissipation technique of the upper extremity among the principles of PNF irradiation affects the flexibility of the hamstring muscle as well as to compare these effects with two other stretching techniques. To achieve the objectives of this study, static stretching, PNF-hold relax, and PNF irradiation was applied. ROM, pressure pain thresholds (PPT), and muscle tone was compared to investigate for the clinical effects.

\section{Methods}

\section{Participants}

Fifty-one healthy men and women in their 20 s and 30 s were recruited through advertisements. Subject selection criteria included those with more than $20^{\circ}$ of knee extension during the active knee extension (AKE) test. Subjects were excluded if they have had a surgical history of shoulder, hip, and knee joints, had a lower extremity injury within 3 months, and those who are undergoing regular exercise and training. All subjects understood the study purpose and agreed to participate by providing their written informed consent. Through the G-power (version 3.1.9.2; Heinrich-Heine-Universität, Düsseldorf, Germany), the minimum size of 51 subjects was identified after calculating the effect size by calculating the values of the main variables before and after intervention in the group of previous studies [9]. This study was conducted under the review of the Institutional Bioethics Committee of Daejeon University (IRB No. 1040647-201906-HR-015-01).

\section{Intervention}

A total of 51 subjects were randomly assigned to one of three groups: 17 subjects in the static stretching group, 17 subjects in the PNF-hold relax group, and 17 subjects in the PNF irradiation group. In all three groups, the parameters were measured in advance and then mediated by each stretching technique. Then, the variables were re-measured (Figure 1). The participants in the study were aware of possible problems beforehand, and the same therapist conducted the experiment to maintain inter-rater reliablity.

\section{Static stretching}

Subjects were instructed to lie down on a solid table with a foam roller ( 5 inches in diameter) under the contralateral knee, which maintained the knee flexed to approxiomately $20^{\circ}$. The subjects used both hands to support the thigh in order to maintain $90^{\circ}$ of hip flexion, and the ankle was maintained in a relaxed flexed position. With the subject's foot placed onto the evaluator's shoulder, the hamstring muscles were maximally stretched, and this position was maintained for 30 seconds (Figure 2) $[9,16]$. This was performed for a total of three times.

\section{Peripheral neuromuscular facilitation: hold-relax}

The intial starting position is equivalent to the starting position of the static stretching method. With the subjects foot placed onto the evaluator's shoulder, at the point when the 


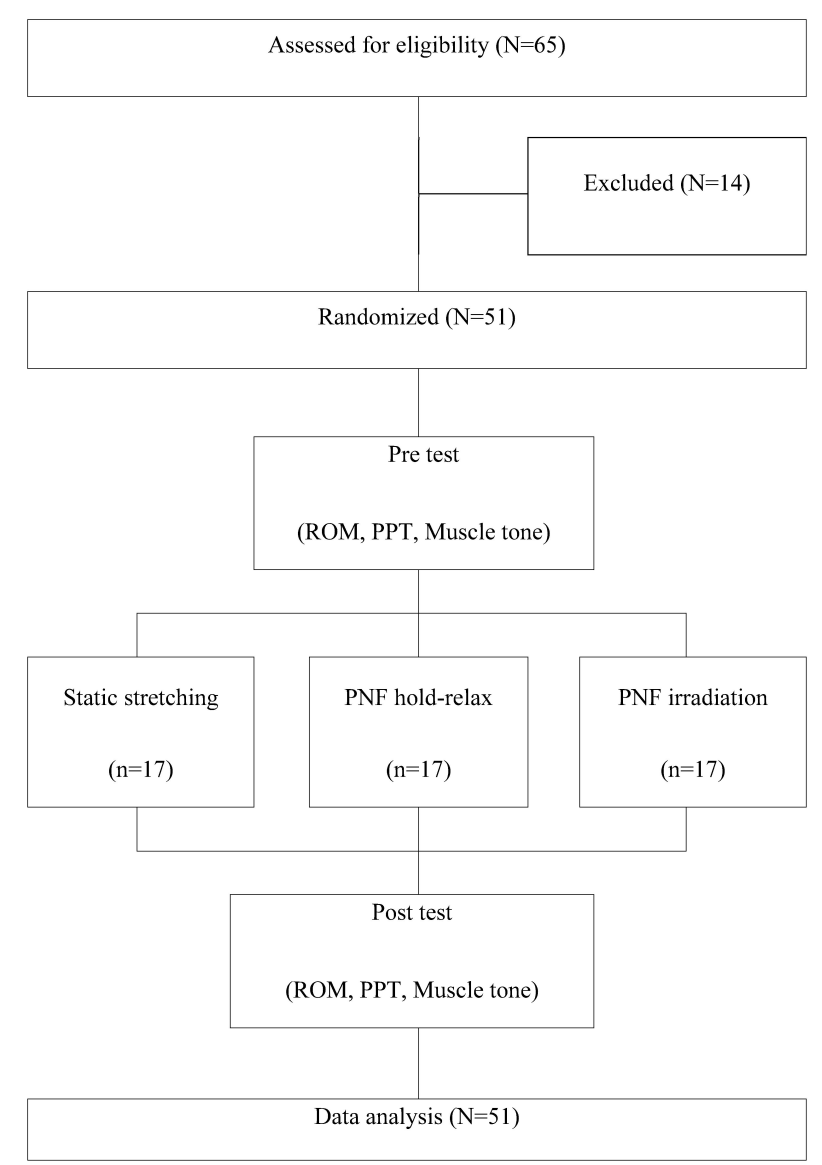

Figure 1. Flow chart. ROM: range of motion, PPT: pressure pain thresholds, PNF: proprioceptive neuromuscular facilitation.

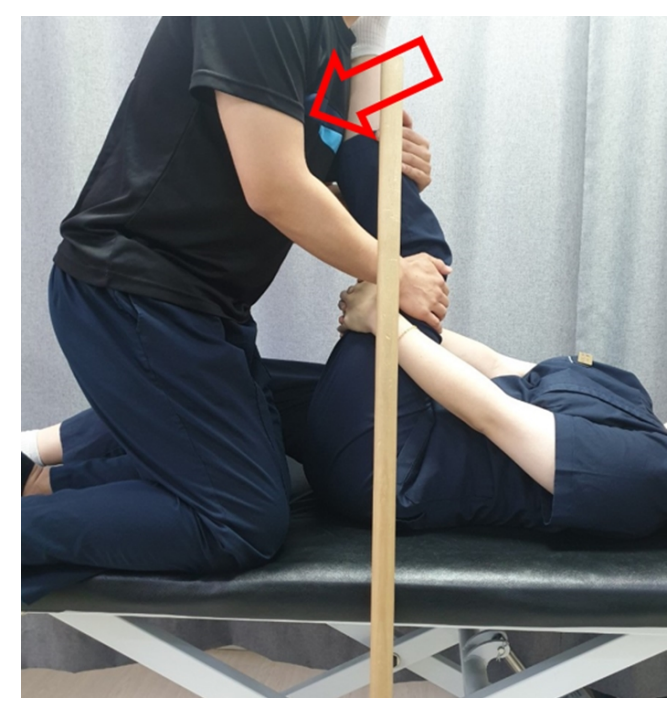

Figure 2. Static stretching.

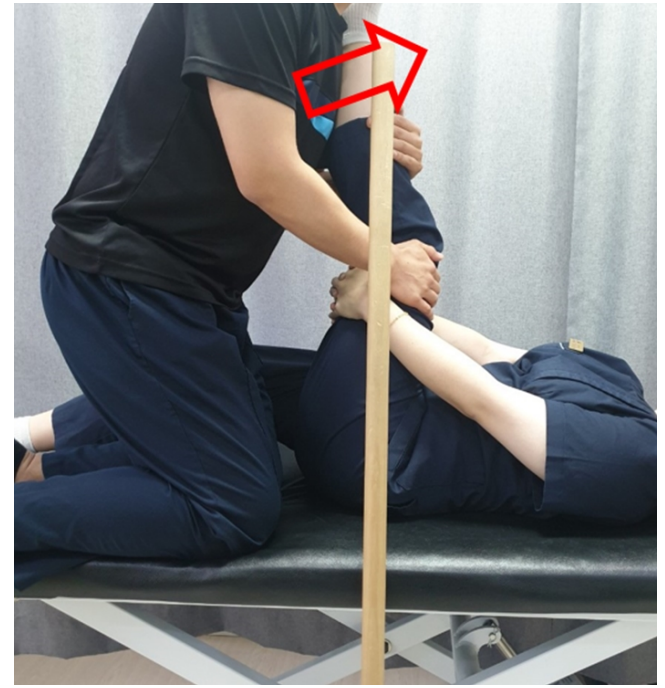

Figure 3. Proprioceptive neuromuscular facilitation hold-relax.

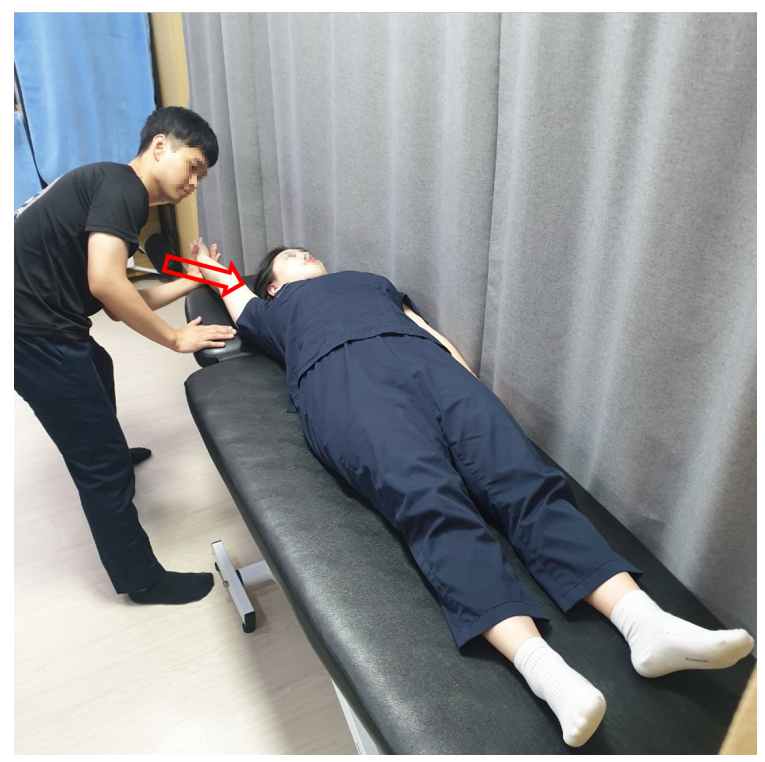

Figure 4. Proprioceptive neuromuscular facilitation irradiation.

subject began to experience pain with maximal stretching, the subject performed maximal isometric contraction of the hamstring muscles for 10 seconds against the resistance of the evaluator, and then relaxed (Figure 3) [9]. This was performed a total of three times.

\section{Proprioceptive neuromuscular facilitation irradiation group}

With subjects lying on a solid table, and at the end of the PNF irradiation pattern method (shoulder-flexion-abduction-lateral rotation) movement, the evaluator applied resistance in the direction from head to toe while the subject main- 
tained the arm raised above the head. The direction of resistance was directed toward the body, the intensity was described as 'more' or 'harder' when producing maximum isometric contractions in the final range, and this posture was maintained for 5 seconds $[14,15]$. During the application of the technique, the waist, pelvis and shoulders were prevented from falling off the floor (Figure 4). This was performed for a total of five times.

\section{Outcome measures}

\section{Range of motion}

The angle measurement for assessing joint ROM was performed using a smartphone app (Clinometer+bubble level; Plaincode Software Solutions, Stephanskirchen, Germany), which can be used as an inclinometer using a tilt sensor. The level of reliability (intra-class correlation coefficient [ICC] $=$ 0.75-0.93) was high (Figure 5) [17].

As a method for assessing joint ROM, modified AKE was performed. In the supine position, the subject maintained approximaly 20 degrees of knee flexion by placing a foam roller ( 5 inches in diameter) under the knee of the contralateral leg being measured in order to stabilize the pelvis during the measurement. In addition, a rod was placed next to the greater trochanter of the leg to be measured, and the subject supported the leg with both hands to maintain $90^{\circ}$ of hip flexion. The knee was placed in extension within the subject's maximal capability, and the inclinometer was placed on the tibial surface of the examination leg in order to measure the angle. After a total of three measurements, the mean value was obtained $[18,19]$.

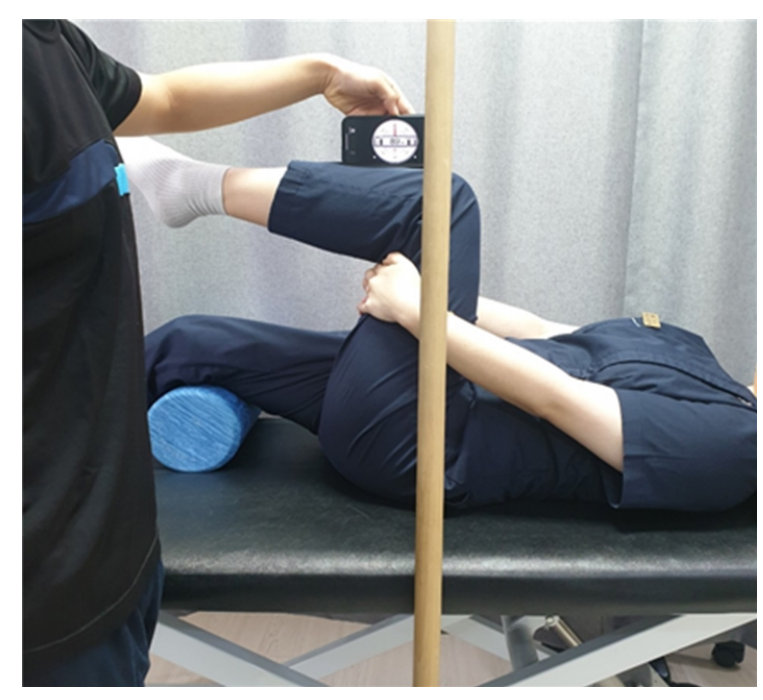

Figure 5. Range of motion.

\section{Pressure pain threshold}

To assess for the level of tissue sensitivity to pressure and the degree of pain, the pressure pain threshold was used, which is a highly repeatable and reliable pressure gauge ( $\mathrm{J}$ TECH Medical Commander, J-Tech, Torrance, CA, USA). It has a high inter-measurement reliability $(\mathrm{ICC}=0.91)$ (Figure 6) [20]. In order to ensure equality in all measurements, a marker was placed at approximaly $1 / 2$ the length of the hamstring muscle, which was between the ischial tuberosity and the popliteal fossa. Pressure was applied by placing the pressure gauge perpendicular to the marked point in prone position [7]. The pressure pain threshold was defined as the time point at which the pressure turned to pain, and this assessment was practiced on the back of the subject's hand. The subject was instructed to make a sound as soon as the subject perceived the pressure as pain, and the pressure value at that moment was recorded [21]. The time interval between measurements was equally 10 seconds, and the mean value was obtained from a total of three measurements.

\section{Muscle tone}

In this study, the Myoton PRO (Myoton AS, Tallinn, Estonia), which was verified in previous studies [22,23], was used for the evaluation of muscle tension (Figure 7). Measurement was conducted in prone position and a measurement probe device (polycarbonate probe, $3 \mathrm{~mm}$ ) was placed vertically at the same position as the pressure pain threshold. When the measurement error (coefficient of variarion, $\mathrm{CV}$ ) was $3 \%$ or more, the measurement was repeated. When the $\mathrm{CV}$ value was $3 \%$ or less, the average value of three measured values

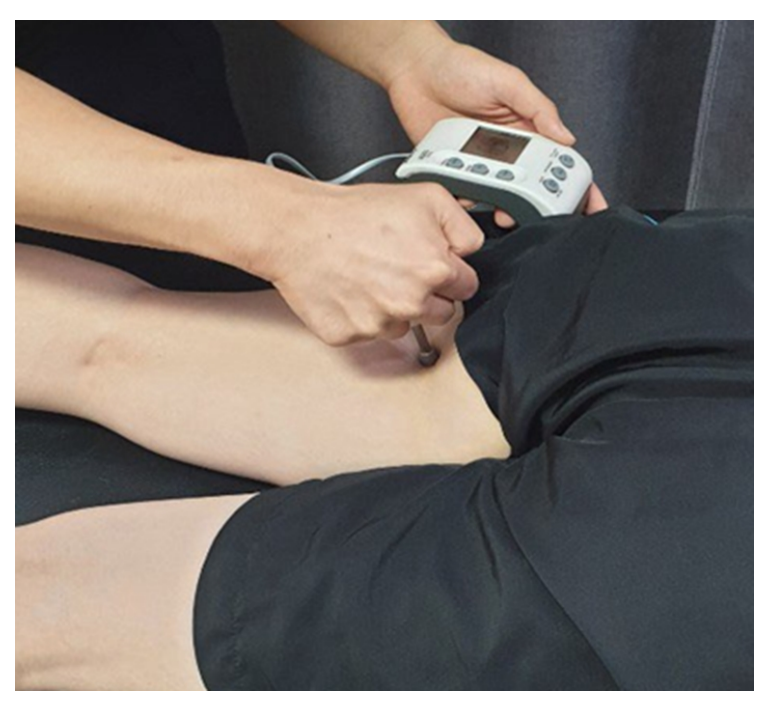

Figure 6. Pressure pain threshold. 
was used, and a high level of internal reliability $(\mathrm{ICC}=0.99)$ was shown [24].

\section{Data and statistical analysis}

The PASW Statistics for Windows, Version 18.0 (SPSS Inc., Chicago, IL, USA) was used for data collection. The general characteristics of the subjects were analyzed by descriptive statistics and are presented as mean and standard deviation (mean \pm standard deviation) values. The ShapiroWilks test was used to verify the normality of the data, in which the data did satisfiy the normality test. The paired t-test was used to compare the difference between the measured variables in each group, and one-way ANOVA was performed to compare the three groups. Post-hoc test was performed by the Scheffe test. The statistical significance level was set at $\alpha=0.05$.

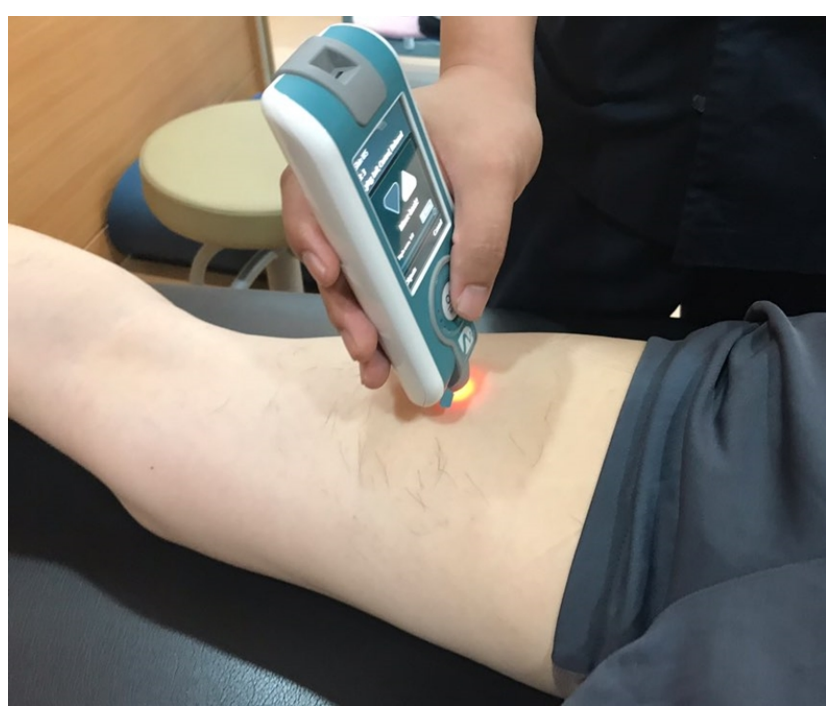

Figure 7. Muscle tone.

\section{Results}

A total of 51 subjects were randomly assigned to the static stretching group $(n=17)$, the PNF-hold relax $(n=17)$ group, and the PNF irradiation ( $\mathrm{n}=17)$ group. The general characteristics of the subjects are as follows (Table 1). The extent of joint movement was significantly increased in the static stretching, PNF-hold relax, and the PNF irradiation group when comparing the pre- and post-intervention values $(p<0.05)$. All three groups showed a significant increase $(p<0.05)$.

PPT were significantly increased in the static stretching, PNF-hold relax, and PNF irradiation group when comparing pre- and post- difference between the three groups.

Muscle tension did not show a significant increase in the static stretching, PNF-hold relax, and the PNF irradiation group in the pre-post intervention comparisons $(p>0.05)$. There was no significant difference between the three groups $(p>0.05)$. Post hoc analysis showed significant differences in the order of PNF-hold relax, static stretching, and PNF irradiation group (Table 2 ).

\section{Discussion}

This study was conducted to investigate the immediate effect of applying static stretching, PNF-hold relax, and PNF irradiation on ROM, pressure pain threshold, and muscle tension on shortened hamstring muscles. The following results were found in this study.

In this study, the application of static stretching and PNF-hold relax showed a significant effect on ROM. Davis et al. [1] reported that significant effects were only found with static stretching for four-weeks, and Bany et al. [15] established the standard for the frequency and duration of static stretching, and when static stretching was applied to the hamstring muscles, there were differences in time and frequency, but they were effective in increasing ROM. The

Table 1. General characteristics of subjects

\begin{tabular}{lcccc}
\hline \multicolumn{1}{c}{ Variable } & Static stretching group $(\mathrm{n}=17)$ & PNF hold-relax group $(\mathrm{n}=17)$ & PNF irradiation group $(\mathrm{n}=17)$ & $p$-value \\
\hline Sex (male/female) & $10 / 7$ & $8 / 9$ & $12 / 5$ & 0.219 \\
Age $(\mathrm{y})$ & $25.58(3.00)$ & $28.64(2.82)$ & $28.23(2.25)$ & 0.892 \\
Height $(\mathrm{cm})$ & $170.05(10.46)$ & $164.88(5.85)$ & $169.47(10.14)$ & 0.201 \\
Weight $(\mathrm{kg})$ & $67.41(13.17)$ & $62.00(14.04)$ & $71.88(18.55)$ & 0.185 \\
\hline
\end{tabular}

Values are presented as number only or mean (SD).

PNF: proprioceptive neuromuscular facilitation. 
Table 2. Comparative analysis of ROM, PPT, muscle tone

$(\mathrm{N}=51)$

\begin{tabular}{|c|c|c|c|c|}
\hline Variable & Static stretching group $(\mathrm{n}=17)$ & PNF hold-relax group $(n=17)$ & PNF irradiation group $(n=17)$ & $p$-value \\
\hline \multicolumn{5}{|l|}{$\operatorname{ROM}\left(^{\circ}\right)$} \\
\hline Pre-test & $54.17(7.38)$ & $52.76(7.71)$ & $48.72(9.00)$ & 0.134 \\
\hline Post-test & $66.17(8.82)$ & $67.88(9.03)$ & $58.16(11.36)$ & 0.013 \\
\hline$p$-value & $<0.001$ & $<0.001$ & $<0.001$ & \\
\hline Change & $12.00(6.66)$ & $15.11(5.76)$ & $9.44(7.04)$ & 0.048 \\
\hline \multicolumn{5}{|l|}{ PPT (lb) } \\
\hline Pre-test & $242.90(95.09)$ & $255.49(100.73)$ & $250.24(99.01)$ & 0.932 \\
\hline Post-test & $287.47(101.91)$ & $287.43(118.67)$ & $276.31(110.94)$ & 0.944 \\
\hline$p$-value & $<0.001$ & 0.001 & 0.002 & \\
\hline Change & $44.57(28.42)$ & $31.94(33.67)$ & $26.07(28.91)$ & 0.204 \\
\hline \multicolumn{5}{|c|}{ Muscle tone $(\mathrm{Hz})$} \\
\hline Pre-test & $14.58(1.85)$ & $14.28(1.35)$ & $14.70(1.44)$ & 0.710 \\
\hline Post-test & $14.52(2.05)$ & $14.29(1.39)$ & $14.52(1.65)$ & 0.900 \\
\hline$p$-value & 0.779 & 0.974 & 0.103 & \\
\hline Change & $-0.52(0.76)$ & $0.01(0.73)$ & $-0.19(0.46)$ & 0.670 \\
\hline
\end{tabular}

Values are presented as mean (SD).

ROM: range of motion, PPT: pressure pain thresholds, PNF: proprioceptive neuromuscular facilitation.

hold-relax method has the advantage of being able to be performed within the range where pain does not occur, supported by studies by [2], Oh [25] and Kim et al. [26]. In addition, the PNF-hold relax method uses a dissipation effect, which showed a significant increase in ROM. The PNF irradiation method applied to the unilateral upper limb showed a significant increase in muscle activity of the contralateral lower extremity [15], and Lee et al. [27] showed a significant increase in neck muscle activity when applying the lower limb pattern. Sherrington [10] reported that the muscles showed greater relaxation after a strong contraction. Thus, this study showed significant results by inducing relaxation after contraction of the lower extremity by using the dissipation effect of the upper limbs.

Many studies have reported that cross-training exercises improve muscle strength, function, and endurance, allowing transverse movement to the untrained limb [28]. Pink [29] proposed two hypotheses, which were hyperactivity through direct exercise and stabilization of the opposite side for limb stability. This is supported by the work of Munn et al. [30] and Hellebrandt [31], in which they stated that it is due to the synergistic joint action of many muscle groups. The pattern of PNF applied to the body segment influenced the muscle activity of other parts of the body, which is consistent with the direction of this study.

All three stretches in this study showed significant results in improving the pressure pain threshold. Stimulation applied to the topical area inhibits the excitation of A-delta and
$\mathrm{C}$ fibers, while it excites the harmless receptors such as A-alpha and A-beta fibers, which blocks the synapses that transmit pain infromation to higher center neurons, thus reducing pain transmission and altering tissue sensitivity. Cutaneous sensory changes induced by mechanical stimulation showed significant results of increasing PPT [32]. There were significant results in hamstring flexibility, pressure pain threshold, and muscle tension in both the extracorporeal shock wave group and the extracorporeal shock wave group that has included stretching techniques [33]. Based on these previous studies, it can be seen that the stimulation caused by stretching may affect the threshold value for pain.

Rosenbaum and Hennig [34] noted that stretching can reduce the risk of injury, and Wilson et al. [35] stated that flexibility training results in improved performance.

Witvrouw et al. [36] stated that pain tends to be increased by direct stretching application, and the results of this study suggest that the PNF irradiation method can be used to safely stretch the hamstring muscle instead of the direct stretching method.

In order to investigate the effect of stretching, muscle tension was assessed among the muscle characteristics, however, all three stretches showed insignificant results.

Previous studies also showed that the effect of stretching was not significant on muscle tension [7,37]. These findings suggest that postural changes may have affected the re-assessment before and after intervention. More detailed research on this is necessary. 
According to the results of this study, the increase of muscle activity appears to have had an effect on ROM. This is considered to be clinically significant in that it can prevent degeneration of joints and muscles through indirect methods rather than direct movement to disorders related to central or peripheral injury, fixation, pain, burns, fractures and prevention, and muscle atrophy.

The limitations of this study are as follows. First, since there was no control in daily life, and there may have been some variations in the measured variables.

Second, it is difficult to generalize the results to patients since the study subjects were limited to healthy adults. Third, only immediate effects on ROM, pressure pain threshold, and muscle tone were observed.

Therefore, future studies will need to study a diversity of age groups and the long-term effects of the intervention period.

\section{Conflict of Interest}

The authors declared no potential conflicts of interest with respect to the authorship and/or publication of this article.

\section{References}

1. Davis DS, Ashby PE, McCale KL, McQuain JA, Wine JM. The effectiveness of 3 stretching techniques on hamstring flexibility using consistent stretching parameters. J Strength Cond Res 2005; 19:27-32.

2. Sullivan MK, Dejulia JJ, Worrell TW. Effect of pelvic position and stretching method on hamstring muscle flexibility. Med Sci Sports Exerc 1992;24:1383-9.

3. Kisner C, Colby LA. Therapeutic exercise foundations and techniques. 6th ed. Philadelphia (PA): F.A. Davis Company; 2012.

4. Bahr R, Holme I. Risk factors for sports injuries--a methodological approach. Br J Sports Med 2003;37:384-92.

5. Jung JH, Choi WJ, Lee YH, Kim JW, Kim HJ, Lee KH, et al. Immediate effect of self-myofascial release on hamstring flexibility. Phys Ther Rehabil Sci 2017;6:45-51.

6. Jeong HM, Shim JH, Suh HR. The passive stretching, massage, and muscle energy technique effects on range of motion, strength, and pressure pain threshold in musculoskeletal neck pain of young adults. Phys Ther Rehabil Sci 2017;6:196-201.

7. Park HY, Lee MM. A comparison of the effect of stretching technique on hamstring muscle for flexibility, strength, pressure pain threshold value and muscle tone. J Korean Soc Phys Med 2017; 12:39-46.

8. Bandy WD, Sanders B. Therapeutic exercise for physical therapist assistants. Baltimore, MD: Lippincott, Williams \& Wilkins; 2001.

9. Puentedura EJ, Huijbregts PA, Celeste S, Edwards D, In A,
Landers MR, et al. Immediate effects of quantified hamstring stretching: hold-relax proprioceptive neuromuscular facilitation versus static stretching. Phys Ther Sport 2011;12:122-6.

10. Sherrington CS. On plastic tonus and proprioceptive reflexes. J Nerv Ment Dis 1923;57:589.

11. Kim JM, Yi CH. Neurological physical therapy. 2th ed. Seoul: Jungdam Pub; 2001.

12. Hellebrandt FA. Application of the overload principle to muscle training in man. Am J Phys Med 1958;37:278-83.

13. Adler SS, Beckers D, Buck M. PNF in practice: an illustrated guide. 2nd rev. ed. New York: Springer; 2000.

14. Han HW, Kim SS. Effect of close kinetic chain and open kinetic chain position on proprioceptive neuromuscular facilitation applied to the unilateral upper extremity on the muscle activation of lower extremity. J Korean Proprio Neuromuscul Facil Assoc 2009; 7:17-27.

15. Kim KH. Effect of proprioceptive neuromuscular facilitation applied to the unilateral upper extremity on the muscle activation of contralrteral lower extremity [Master thesis]. Seoul: Eulji University; 2005.

16. Bandy WD, Irion JM, Briggler M. The effect of time and frequency of static stretching on flexibility of the hamstring muscles. Phys Ther 1997;77:1090-6.

17. Park IW, Lim OB, Park KN, Yi CH. Intra -and inter -rater reliability of measuring passive range of shoulder motion with smartphone and goniometer in patients with stroke. Phys Ther Korea 2014;21:1-12.

18. Connor SO, McCaffrey N, Whyte E, Moran K. Reliability of a modified active knee extension test for assessment of hamstring flexibility. Int J Athl Ther Train 2015;20:32-6.

19. Shimon JM, Darden GF, Martinez R, Clouse-Snell J. Initial reliability and validity of the lift-and-raise hamstring test. J Strength Cond Res 2010;24:517-21.

20. Chesterton LS, Sim J, Wright CC, Foster NE. Interrater reliability of algometry in measuring pressure pain thresholds in healthy humans, using multiple raters. Clin J Pain 2007;23:7606.

21. Chae YW. The measurement of forward head posture and pressure pain threshold in neck muscle. J Kor Soc Phys Ther 2002; 14:117-24.

22. Kim CS, Kim MK. Mechanical properties and physical fitness of trunk muscles using Myoton. Korean J Phys Educ 2016;55:63342.

23. Agyapong-Badu S, Warner M, Samuel D, Stokes M. Measurement of ageing effects on muscle tone and mechanical properties of rectus femoris and biceps brachii in healthy males and females using a novel hand-held myometric device. Arch Gerontol Geriatr 2016;62:59-67.

24. Shin JM. A study on comparison of mechanical properties of muscles according to various contraction levels using Myoton [Master thesis]. Seoul: Sungkyunkwan University; 2019.

25. Oh YT. Effect of hold-relax technique for college students with hamstring shortening. J Korean Soc Phys Med 2013;8:433-41.

26. Kim JS, Woo YK, Ki KI. The effects of hold-relax techniques after inducing delayed muscle pain on the pain and range of motion of joints. PNF Mov 2016;14:15-21.

27. Lee MK, Kim JM, Park HK, Kim WH. The effects of proprioceptive neuromuscular facilitation leg patterns on the muscle ac- 
tivation of neck flexors. Phys Ther Korea 2008;15:46-53.

28. Thomas WM. Anatomy trains: myofascial meridians for manual and movement therapists. Churchill Livingstone, Elservier Science Limited; 2002.

29. Pink M. Contralateral effects of upper extremity proprioceptive neuromuscular facilitation patterns. Phys Ther 1981;61:1158-62.

30. Munn J, Herbert RD, Gandevia SC. Contralateral effects of unilateral resistance training: a meta-analysis. J Appl Physiol (1985) 2004;96:1861-6.

31. Hellebrandt FA. Cross education; ipsilateral and contralateral effects of unimanual training. J Appl Physiol 1951;4:136-44.

32. Kim DH, Lee SH, Lee BH. Effects of mechanical intervention on cutaneous sensory change and pressure pain threshold in the same spinal segment of myofascial pain. Phys Ther Rehabil Sci 2019;8:15-21.

33. Kim HR. Effects of extracorporeal shock wave and stretching technique on flexibility, muscle tone and pressure pain threshold of shortened hamstring [Master thesis]. Seoul: Namseoul University; 2017.

34. Rosenbaum D, Hennig EM. The influence of stretching and warm-up exercises on Achilles tendon reflex activity. J Sports Sci 1995;13:481-90.

35. Wilson GJ, Elliott BC, Wood GA. Stretch shorten cycle performance enhancement through flexibility training. Med Sci Sports Exerc 1992;24:116-23.

36. Witvrouw E, Mahieu N, Danneels L, McNair P. Stretching and injury prevention: an obscure relationship. Sports Med 2004;34: 443-9.

37. Rihvk I, Clough A, Clough P. Investigation to compare static stretching and proprioceptive neuromuscular facilitation contract $^{-}$relax stretching effects on the visco-elastic parameters of the biceps femoris muscle. Int Musculoskel Med 2010;32:15762. 